\title{
Intermetallic Platinum Alloy Nanoparticles and Single Atoms Hybrid Electrocatalysts for Proton Exchange Membrane Fuel Cells
}

\section{Minhua Shao ( $\sim$ kemshao@ust.hk)}

Hong Kong University of Science and Technology https://orcid.org/0000-0003-4496-0057

Fei Xiao

The Hong Kong University of Science and Technology

Qi Wang

Southern University of Science and Technology

Gui-Liang Xu

Chemical Science and Engineering Division, Argonne National Laboratory

\section{Xueping Qin}

The Hong Kong University of Science and Technology

Inhui Hwang

Advanced Photon Source, Argonne National Laboratory

Chengjun Sun

Argonne National Laboratory

Hua Wei

Northwestern Polytechnical University

Hsi-wen Wu

The Hong Kong University of Science and Technology

Shangqian Zhu

The Hong Kong University of Science and Technology https://orcid.org/0000-0002-5813-9588 Jin-Cheng Li

The Hong Kong University of Science and Technology

Jiangan Wang

Northwestern Polytechnical University

\section{Yuanming Zhu}

Southern University of Science and Technology

\section{Duojie Wu}

Southern University of Science and Technology

\section{Zidong Wei}

Chongqing University https://orcid.org/0000-0001-8001-9729

\section{Meng Gu}


Southern University of Science and Technology https://orcid.org/0000-0002-5126-9611

\section{Khalil Amine}

Chemical Science and Engineering Division, Argonne National Laboratory https://orcid.org/0000-00019206-3719

\section{Physical Sciences - Article}

Keywords: fuel cells, electrocatalysts, electrochemical devices, nanoparticles

Posted Date: July 13th, 2021

DOl: https://doi.org/10.21203/rs.3.rs-685784/v1

License: (9) This work is licensed under a Creative Commons Attribution 4.0 International License. Read Full License

Version of Record: A version of this preprint was published at Nature Catalysis on June 2nd, 2022. See the published version at https://doi.org/10.1038/s41929-022-00796-1. 


\section{Abstract}

Proton exchange membrane fuel cell converts hydrogen and oxygen into electricity with zero emission ${ }^{1}$. The high cost and low durability of Pt-based electrocatalysts for oxygen reduction reaction hinder its wide applications ${ }^{2,3}$. The development of non-precious metal electrocatalysts also reaches the bottleneck because of the low activity and durability ${ }^{4,5}$. Here we rationally design a hybrid electrocatalyst consisting of atomically dispersed Pt and Fe single atoms and intermetallic PtFe alloy nanoparticles. The Pt mass activity of the hybrid catalyst is 3.5 times higher than that of commercial Pt/C in a fuel cell. More importantly, the fuel cell with an ultra-low Pt loading in the cathode $\left(0.015 \mathrm{mg}_{\mathrm{Pt}} \mathrm{cm}^{-2}\right)$ shows unprecedented durability, with $93.6 \%$ activity retention after 100,000 cycles and no noticeable current drop at $0.6 \mathrm{~V}$ for at least $206 \mathrm{~h}$. These results highlight the importance of the synergistic effects among active sites in hybrid electrocatalysts and provide an alternative way to design more active and durable low-Pt electrocatalysts for electrochemical devices.

\section{Introduction}

Proton exchange membrane fuel cells (PEMFCs) as a promising clean energy conversion technology have gained considerable attention. However, the high cost and low durability of Pt-based nanocatalysts for the cathodic oxygen reduction reaction (ORR) hinder the wide adoption of this technology ${ }^{2,6}$. According to the ultimate cost target of $\$ 30 \mathrm{~kW}^{-1}$ for the fuel-cell stack, the Pt loading in the catalyst layers must be below $0.125 \mathrm{mg} \mathrm{cm}^{-2}$. However, as the Pt loading decreases, the oxygen transfer resistances increase because of limited accessible active sites, resulting in more deteriorated durability ${ }^{7}$. Thus, the ambition of developing low-Pt-loading cathodes poses great challenges in the areas of Pt utilization and intrinsic durability of Pt-based electrocatalysts. Despite great efforts on the development of advanced Pt-based catalysts to improve the Pt utilization and mass activity (MA) toward ORR ${ }^{1,8}$, their high activities/durability measured in liquid cells have rarely been realized in fuel cells. On the other hand, carbon-based Pt group metal (PGM)-free ORR electrocatalysts consisting of highly dispersed transitionmetal single atoms in nitrogen-coordinated carbon surfaces (Me-N-C) are promising candidates to replace $\mathrm{Pt}^{5}$. Unfortunately, the poor durability of Me-N-C has limited their practical applications ${ }^{9}$. Recently, Liu et al. reported a hybrid catalyst consisting of Pt-Co alloy nanoparticles supported on Co-N-C with an unprecedented ORR activity $\left(1.77 \mathrm{~A} \mathrm{mg}_{\mathrm{Pt}}{ }^{-1} \text { at } 0.9 \mathrm{~V}\right)^{10}$. Despite the excellent Pt MA of this hybrid ORR catalyst, it still suffered significant activity losses during potential cycling (83\% after 30,000 cycles between 0.6 and $0.95 \mathrm{~V}$ ) and potential hold (45\% after $22 \mathrm{~h}$ at $0.75 \mathrm{~V})^{10}$.

Herein, we report a hybrid electrocatalyst (denoted as Pt-Fe-N-C) consisting of multiple types of active sites that shows not only a tenfold higher Pt MA, but also unprecedented durability. The performance loss is negligible even after 100,000 potential cycles, and no current drop is observed for at least $206 \mathrm{~h}$ at 0.6 $\mathrm{V}$ in a fuel cell test with an ultra-low Pt loading $\left(0.015 \mathrm{mg}_{\mathrm{Pt}} \mathrm{cm}^{-2}\right)$ in the cathode. To the best of our 
knowledge, no comparable durability for a cathode with an ultra-low Pt loading has previously been reported in fuel cells.

\section{Structure And Composition Of Pt-Fe-N-c}

Figure 1a shows a typical transmission electron microscopy (TEM) image of the as-synthesized Pt-Fe-N-C catalyst, clearly revealing nanoparticles with a main size distribution of 2-3 nm (Supplementary Fig. 1) dispersed on a carbon substrate with a Brunauer-Emmett-Teller surface area of $750 \mathrm{~m}^{2} \mathrm{~g}^{-1}$ (Supplementary Fig. 2). High-angle annular dark-field scanning transmission electron microscopy (HAADF-STEM) images of Pt-Fe-N-C (Fig. 1b and Supplementary Fig. 3) show a high density of isolated atoms anchored on the carbon substrate in addition to nanoparticles. A representative atomically resolved STEM image of a single particle (Fig. 1C) shows the atomic arrangement view along the [100] direction. The characterized atom contrast as well as the lattice distance of $3.78 \AA$ (001) reveals an ordered structure, which is consistent with the atomic model and simulated STEM image of a facecentered-tetragonal PtFe structure. It is worth noting that the ordered structure can be clearly identified in almost every nanoparticle (Supplementary Fig. 3). Two sets of bright spots, distinguished by their Zcontrast difference ${ }^{11}$, could be detected in Fig. $1 \mathrm{~d}$ and Supplementary Fig. 4. As shown in Fig. 1e, the local electron energy loss spectroscopy (EELS) profile of the nanoparticle shows strong Fe and $\mathrm{O}$ signals, while the Pt signal could not be detected owing to the high energy loss of the Pt M-edge ${ }^{12}$. The profile of the single atom in a blue dashed circle shows weak Fe and $\mathrm{N}$ signals, suggesting the weaker spot to be an Fe-N moiety. In contrast, the profile of the atom in a red dashed circle only shows a weak $\mathrm{N}$ signal, indicating the brighter spot to be a Pt-N moiety. These results are in good agreement with their contrast differences in STEM images.

According to the inductively coupled plasma mass spectrometry results, the metal loadings in Pt-Fe-N-C are $2.0 \mathrm{wt} \% \mathrm{Fe}_{\mathrm{e}}$ and $1.7 \mathrm{wt} \% \mathrm{Pt}$. The oxidation states of metals and types of nitrogen dopant are characterized by X-ray photoelectron spectroscopy in Supplementary Fig. 5. The structure of Pt-Fe-N-C was further characterized by X-ray absorption spectroscopy (XAS). Indicating from X-ray absorption nearedge structure (XANES) result, there was no obvious difference in $\mathrm{Pt}_{\mathrm{L}_{3}}$-edge (Fig. 1f) in the pre-edge region in comparison with a metallic Pt foil. The stronger intensity of the white line for Pt-Fe-N-C, resulting from the electron transfer from Pt $5 d$ to Fe $3 d$ orbitals, suggested that Pt is in the oxidized form in the Pt$\mathrm{Fe}-\mathrm{N}-\mathrm{C}^{13}$. For the Fe K-edge in Fig. $1 \mathrm{~g}$, the intensity of the pre-edge peak is the highest for the Pt-Fe-N-C sample, while the white-line intensity has decreased dramatically compared with $\mathrm{Fe}-\mathrm{N}-\mathrm{C}$ and Fe oxides. The formation of Pt-Fe alloys and coordination information of Pt and Fe single atoms were confirmed by Fourier transforms of extended X-ray absorption fine structure data (EXAFS, Supplementary Fig. 6) and relative fitting results (Supplementary Fig. 7 and Supplementary Table 1).

\section{Performance Evaluation Of Pt-Fe-N-C}

A cyclic voltammogram (CV) curve of Pt-Fe-N-C did not present profound hydrogen adsorption/desorption peaks characteristic of Pt because of the ultra-low Pt loading (Supplementary Fig. 8). Pt-Fe-N-C showed a 
significantly improved ORR activity over Fe-N-C, with the half-wave potential (HWP) shifting from 0.790 to $0.909 \mathrm{~V}$ (Supplementary Fig. 9). The corresponding Pt MA of Pt-Fe-N-C at $0.9 \mathrm{~V}$ reached $1.74 \mathrm{~A} \mathrm{mg}_{\mathrm{Pt}}{ }^{-1}$, which was more than ten times that of $\mathrm{Pt} / \mathrm{C}\left(0.18 \mathrm{~A} \mathrm{mg}_{\mathrm{Pt}}{ }^{-1}\right)$ and much higher than most of the Pt-based electrocatalysts (Supplementary Table 2). The calculated maximum hydrogen peroxide yield $\left(\mathrm{H}_{2} \mathrm{O}_{2} \%\right)$ and the electron transfer number were $2.4 \%$ and 4 , respectively, suggesting a complete four-electron transfer reaction. The durability of Pt-Fe-N-C catalyst was evaluated during potential cycling (Supplementary Figs. 10-11). The HWP of Pt-Fe-N-C showed a drop of only $15 \mathrm{mV}$ after 40,000 cycles between 0.6 and $1.0 \mathrm{~V}$, much better than that of Fe-N-C (16 mV) and Pt/C (10 mV) after only 10,000 cycles (Supplementary Fig. 12).

The fuel-cell performance of Fe-N-C, Pt-N-C, Pt/C, and Pt-Fe-N-C catalysts was evaluated in an $\mathrm{H}_{2} / \mathrm{O}_{2}$ environment and compared in Fig. 2a. The fuel cells with Pt-N-C and Fe-N-C reached peak power densities of 0.32 and $0.66 \mathrm{~W} \mathrm{~cm}^{-2}$, respectively, which were comparable to values reported in the literature $\mathrm{w}^{14,15}$. The fuel cell showed significantly enhanced performance with Pt-Fe-N-C in the cathode, achieving a power density of $0.95 \mathrm{~W} \mathrm{~cm}^{-2}$ at $2.0 \mathrm{~A} \mathrm{~cm}^{-2}$. Even though the power density was lower than that of $\mathrm{Pt} / \mathrm{C}$ $\left(1.3 \mathrm{~W} \mathrm{~cm}^{-2}\right)$, it is worth noting that the Pt loading in the latter was 7 times higher $\left(0.015 \mathrm{vs} 0.1 \mathrm{mg}_{\mathrm{Pt}} \mathrm{cm}^{-}\right.$ ${ }^{2}$ ). The corresponding Pt MA of Pt-Fe-N-C was $0.94 \mathrm{~A} \mathrm{mg}^{-1}$ at $0.9 \mathrm{~V}$; that value was 3.5 times higher than $\mathrm{Pt} / \mathrm{C}\left(0.27 \mathrm{~A} \mathrm{mg}^{-1}\right)$, and twice that of the 2025 activity target $\left(0.44 \mathrm{~A} \mathrm{mg}_{\mathrm{Pt}}{ }^{-1}\right)$ set by the U.S. Department of Energy (DOE). The volumetric activity at $0.8 \mathrm{~V}$ was calculated to be $897 \mathrm{~A} \mathrm{~cm}^{-3} 16$, which exceeded the DOE's $300 \mathrm{~A} \mathrm{~cm}^{-3}$ target for PGM-free catalysts. The fuel cell performance of Pt-Fe-N-C is superior to the majority of reported low-Pt-loading electrodes and hybrid electrocatalysts (Supplementary Table 2).

The cells assembled with Pt-Fe-N-C, Pt/C and Fe-N-C cathodes were further subjected to accelerated durability testing under repeated square-wave cycles at 0.6 and $0.95 \mathrm{~V}$ by holding at each potential for 3 $\mathrm{s}$, following the DOE testing protocol. As shown in Fig. $2 \mathrm{~b}$, the fuel cell polarization curves with the Pt-Fe$\mathrm{N}-\mathrm{C}$ cathode showed no change after 30,000 cycles, and a negligible change after 100,000 cycles. The cell retained the MA of $0.88 \mathrm{~A} \mathrm{mg}_{\mathrm{Pt}}{ }^{-1}$ at $0.9 \mathrm{~V}$ and the power density of $0.90 \mathrm{~W} \mathrm{~cm}^{-2}$ at $2.0 \mathrm{~A} \mathrm{~cm}^{-2}$ even after 100,000 cycles. These results surpassed DOE's durability goal of less than $40 \%$ MA loss after 30,000 cycles. In comparison, Pt/C and Fe-N-C cathodes showed substantial performance loss after 30,000 cycles (Supplementary Fig. 13).

The morphology and structure of Pt-Fe-N-C catalyst after 100,000 cycles in a fuel cell were further analyzed by STEM-EELS. Abundant single atoms with the preservation of $\mathrm{N}$ coordinated configuration were still uniformly distributed on the carbon support (Fig. 3a, b). However, the structure and composition of nanoparticles did change during potential cycling (Supplementary Fig. 14). If the particle size was smaller than 4 nm, a solid PtFe@Pt core-shell structure was formed (Fig. 3c), indicating by the lattice spacing of $0.191 \mathrm{~nm}$ for PtFe (002) in the core and $0.204 \mathrm{~nm}$ for Pt (002) in the shell. This conclusion was further supported by the line intensity profile (Fig. 3d). A periodic oscillation of intensity in the center and monotonicity in the shell were observed, which can be attributed to the contrast differences between 
Pt and Fe in an ordered lattice. Bigger particles tended to form a percolated structure (Fig. 3e) with a lattice spacing of $0.204 \mathrm{~nm}$, which is close to the spacing of Pt (002). The energy-dispersive X-ray spectroscopy (EDX) line profile of Pt (Figs. 3f, g) shows a clear concavity in the middle of the particle, indicating the formation of a pit in the nanoparticle. Relative EDX mapping (Supplementary Fig. 15) also implies the formation of a Pt-rich percolated structure. Similar phenomena have been observed in Pt-Ni alloy nanoparticles during potential cycling ${ }^{17}$. It is worth noting that the majority of the PtFe nanoparticles were transformed into a more stable core-shell structure, which played an important role in achieving the unmatched durability of Pt-Fe-N-C. The high durability of intermetallic nanoparticles has been reported by other groups ${ }^{18}$.

A chronoamperometric test at a voltage of $0.6 \mathrm{~V}$ under $\mathrm{H}_{2}$ /air was also conducted. As shown in Fig. 3c, a Pt-Fe-N-C cathode showed a nearly constant current density during the 206-h measurement, while a Pt/C cathode with a much higher Pt loading suffered rapid deterioration, losing approximately 55\% of the current density after only $100 \mathrm{~h}$. For Fe-N-C, the current density drop was even faster, with $75 \%$ loss after $62 \mathrm{~h}$, which was similar to results reported in the literature ${ }^{19,20}$. Iron is a concern for Nafion-based membranes and ionomers because of the Fenton reaction ${ }^{21}$. The $\mathrm{F}^{-}$concentrations in effluent water at $0.6 \mathrm{~V}$ were monitored as a function of time to assess their degradation rate. As shown in Fig. 2d, Fe-N-C always had a higher $\mathrm{F}^{-}$concentration than $\mathrm{Pt} / \mathrm{C}$ and $\mathrm{Pt}-\mathrm{Fe}-\mathrm{N}-\mathrm{C}$ catalysts. The concentration of $\mathrm{F}^{-}$in the first $120 \mathrm{~h}$ for Pt-Fe-N-C was higher than that of Pt/C, possibly because of a larger number of ionomers in the cathode electrode. The concentration continued to decrease and reached a level similar to that of $\mathrm{Pt} / \mathrm{C}$ at $206 \mathrm{~h}$. This result clearly demonstrates that the degradation rates of membranes and ionomers in the Pt-Fe-N-C cell are much slower than those in the Fe-N-C cell, partially because of the lower level of $\mathrm{H}_{2} \mathrm{O}_{2}$ in the former.

\section{Theoretical Study}

Density functional theory (DFT) calculations were performed to explore the origins of the high activity and durability of the hybrid electrocatalyst. Several simulation models were constructed to represent the possible types of active sites (Supplementary Figs. 15-18 and Table 3), including a single atom $\left(\mathrm{Pt}-\mathrm{N}_{1} \mathrm{C}_{3}\right.$, Pt- $\mathrm{N}_{2} \mathrm{C}_{2}$, and Fe- $\mathrm{N}_{1} \mathrm{C}_{3}$ ), Fe-Pt dual metal, and the $\mathrm{Pt}_{\mathrm{ML}} / \mathrm{PtFe}(111)$ core-shell structure (one-monolayer [ML] Pt skin on PtFe(111) substrate). Pure Pt(111) was also included for comparison. The corresponding adsorption structures of reaction intermediates $\left({ }^{*} \mathrm{OOH},{ }^{\star} \mathrm{O}\right.$ and $\left.{ }^{\star} \mathrm{OH}\right)$ on carbon-based models and $\mathrm{Pt}_{\mathrm{ML}} / \mathrm{PtFe}(111)$ are shown in Supplementary Fig. 19 and Fig. 20, respectively. As shown in Fig. 4a and Supplementary Table 4, $\mathrm{Pt}-\mathrm{N}_{1} \mathrm{C}_{3}$ exhibited the best ORR activity, with a downhill trend across all of the elementary reactions except the last ${ }^{*} \mathrm{OH}$ protonation step, and the energy barrier during the ORR was

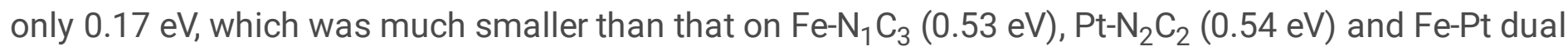
metal $(0.75 \mathrm{eV})$. The $\mathrm{Pt}_{\mathrm{ML}} / \mathrm{PtFe}(111)$ was also predicted to be active for ORR because of a low energy barrier of $0.18 \mathrm{eV}$ in the final ${ }^{*} \mathrm{OH}$ protonation step, which was close to that on $\mathrm{Pt}-\mathrm{N}_{1} \mathrm{C}_{3}(0.17 \mathrm{eV})$. Such a core-shell structure with a 1-ML Pt skin shows better ORR activity than $\mathrm{Pt}(111)$ because of the weaker bindings to reaction intermediates, especially for * $\mathrm{O}$ and ${ }^{*} \mathrm{OH}$. Simulations were also conducted on 
$2 \mathrm{Pt}_{\mathrm{ML}} / \mathrm{PtFe}(111)$ and $3 \mathrm{Pt}_{\mathrm{ML}} / \mathrm{PtFe}(111)$. As shown in Supplementary Fig. 21, all Pt skins showed better ORR activities than pure Pt. Among them, $\mathrm{Pt}_{\mathrm{ML}} / \mathrm{PtFe}(111)$ was the best, with the lowest barrier for the ${ }^{*} \mathrm{OH}$-to- $\mathrm{H}_{2} \mathrm{O}$ step. Thus, $\mathrm{Pt}-\mathrm{N}_{1} \mathrm{C}_{3}$ and core-shell nanoparticles formed after leaching $\mathrm{Fe}$ in the surface and sub-surfaces were proposed to be the most active sites in Pt-Fe-N-C.

One of the major concerns with Me-N-C catalysts in fuel cells is the formation of a large amount of $\mathrm{H}_{2} \mathrm{O}_{2}$ as the final product, which is detrimental to the membrane and ionomers ${ }^{22}$. In our hybrid catalysts, $\mathrm{H}_{2} \mathrm{O}_{2}$ generated at the Fe-N-C or even Pt-N-C sites may be further reduced to $\mathrm{H}_{2} \mathrm{O}$ on nearby Pt-Fe nanoparticles. To validate this hypothesis, $\mathrm{H}_{2} \mathrm{O}_{2}$ reduction on $\mathrm{Pt}_{\mathrm{ML}} / \mathrm{PtFe}(111)$ and $\mathrm{Pt}(111)$ surfaces was compared (Fig. $4 \mathrm{~b}$ and Supplementary Table 5). It turned out that $\mathrm{Pt}_{\mathrm{ML}} / \mathrm{PtFe}(111)$ contributed to the fast $\mathrm{H}_{2} \mathrm{O}_{2}$-to-2*OH conversion and the final ${ }^{*} \mathrm{OH}$-to- $\mathrm{H}_{2} \mathrm{O}$ step was also facile, with an energy barrier of $0.18 \mathrm{eV}$, which was lower than that on Pt(111) (0.34 eV). Thus, the formation of a durable Pt shell on PtFe@Pt during fuel-cell operation and further reduction of $\mathrm{H}_{2} \mathrm{O}_{2}$ on PtFe@Pt produced by single-atom active sites are the main reasons for the exceptional durability.

\section{Conclusions}

In summary, a hybrid ORR electrocatalyst with an ultra-low Pt loading consisting of atomically dispersed $\mathrm{Pt}$ and $\mathrm{Fe}$ single atoms and intermetallic PtFe alloy nanoparticles was successfully synthesized. Excellent performance, including $0.94 \mathrm{~A} \mathrm{mg}_{\mathrm{Pt}}^{-1} \mathrm{MA}$ at $0.9 \mathrm{~V}$ and $0.95 \mathrm{~W} \mathrm{~cm}^{-2}$ power density at $2.0 \mathrm{~A} \mathrm{~cm}^{-2}$, was achieved in a fuel cell. More importantly, this hybrid electrocatalyst demonstrated unprecedented durability, with $93.6 \%$ activity retention after 100,000 cycles and no noticeable current drop at $0.6 \mathrm{~V}$ for at least $206 \mathrm{~h}$. Theoretical simulations suggested that Pt- $\mathrm{N}_{1} \mathrm{C}_{3}, \mathrm{Fe}-\mathrm{N}_{1} \mathrm{C}_{3}$, and PtFe@Pt were all active sites for the ORR. Our results highlight the importance of the synergistic effects among different active sites in hybrid electrocatalysts and provide an alternative way to design more active and durable low-PGM electrocatalysts for fuel cells and other electrochemical devices.

\section{Methods}

\section{Chemicals and Reagents}

Zinc nitrate hexahydrate $\left(\mathrm{Zn}\left(\mathrm{NO}_{3}\right)_{2} \cdot 6 \mathrm{H}_{2} \mathrm{O}, 99.998 \%\right.$ metals basis), ferrous sulfate heptahydrate ( $\mathrm{FeSO}_{4} \cdot 7 \mathrm{H}_{2} \mathrm{O}, 99.95 \%$ metals basis), 2-methylimidazole (98\%), 1,10-phenanthroline monohydrate (99\%), potassium ferricyanide $\left(\mathrm{K}_{3} \mathrm{Fe}(\mathrm{CN})_{6}, 99.95 \%\right.$ metals basis) and potassium hydroxide $(\mathrm{KOH}, 99.99 \%$ metals basis) were purchased from Aladdin. Platinum (II) acetylacetonate ( $\geq 99.98 \%$ trace metals basis), isopropanol (99.9\%) and $5 \mathrm{wt} \% \mathrm{Nafion}^{\mathrm{TM}} 117$ containing solution were purchased from Sigma-Aldrich. Methanol (99.9\%) and ethanol (99.5\%) were ordered from Merck and Scharlau, respectively. Perchloric acid $\left(\mathrm{HClO}_{4}, 70 \%\right.$, veritas double distilled) was purchased from GFS chemicals. D521 Nafion ${ }^{\mathrm{TM}}$ dispersion, gas diffusion layer (GDL, Freudenberg H14C7) and Nafion HP membrane (CL-2019-50, $20 \mu \mathrm{m}$ ) were 
purchased from Fuel Cell Store (https://www.fuelcellstore.com). Commercial Pt/C catalyst (46.4 wt\%, TEC10E50E) was from TKK.

\section{Catalyst synthesis}

Fe doped zeolitic imidazolate framework (Fe doped ZIF-8) and Fe-N-C. Details of the synthesis of Fedoped ZIF-8 can be found elsewhere ${ }^{23,24}$. In brief, $0.95 \mathrm{mM} \mathrm{Zn}\left(\mathrm{NO}_{3}\right)_{2} \cdot 6 \mathrm{H}_{2} \mathrm{O}$ and $0.05 \mathrm{mM} \mathrm{FeSO}_{4} \cdot 7 \mathrm{H}_{2} \mathrm{O}$ as metal sources, and $8.21 \mathrm{~g}$ 2-methylimidazole as the organic linker, were mixed with methanol to form Fedoped ZIF-8. The excess organic linker and metal sources were removed by washing the product three times with absolute ethanol. After drying in a vacuum oven at $80^{\circ} \mathrm{C}$ overnight, Fe-doped ZIF-8 precursor was directly heat-treated in $\operatorname{Ar}$ gas (99.99\% purity) at $1000^{\circ} \mathrm{C}$ for $1 \mathrm{~h}$ to derive the final Fe-N-C catalyst. With these optimized ratios and synthesis protocol, atomically dispersed Fe atoms were uniformly distributed on the $\mathrm{N}-\mathrm{C}$ framework without further acid washes. Detailed characterization of $\mathrm{Fe}-\mathrm{N}-\mathrm{C}$ electrocatalyst is illustrated in ${ }^{23}$. Each Fe atom tended to coordinate with four $\mathrm{N}$ atoms in the plane and two $\mathrm{O}$ atoms in the axial direction. The weight of Fe loading in the final catalyst was around $2 \mathrm{wt} \%$.

Pt-Fe-N-C hybrid electrocatalyst. According to our previous work, impregnation of Fe-N-C with an ultra-low Pt loading could significantly promote the durability of Fe-N-C, while it did not present noticeable activity improvement, especially in the kinetic region ${ }^{24}$. In this follow-up work, ammonia heat treatment was designed to expose more active sites, tailoring the properties of carbon support and the coordination number of single atoms. Secondary Ar pyrolysis after ammonia treatment is designed to stabilize the carbon framework. Thus, Fe-doped ZIF-8 was used as the support for Pt impregnation in this work for simplifying heat treatment protocols. $10 \mathrm{mg}$ platinum (II) acetylacetonate was homogeneously dispersed in $3 \mathrm{~mL}$ ethanol via ultrasonication until the solvent became transparent. In the meantime, $110 \mathrm{mg} \mathrm{1,10-}$ phenanthroline monohydrate dissolved in $10 \mathrm{~mL}$ ethanol was added to the Pt solution to provide a sufficient nitrogen source for Pt coordination. Around $400 \mathrm{mg}$ of Fe-doped ZIF-8 was added to the above solution to form a uniform suspension. After drying at $60^{\circ} \mathrm{C}$ in a vacuum oven overnight, the solid was collected and ball milled $\left(\mathrm{ZrO}_{2}\right.$ ball, $350 \mathrm{rpm}, 4 \mathrm{~h}$ ) to uniformly distribute Pt and $\mathrm{N}$ sources on the Fedoped ZIF-8 support. The mixed precursors were first treated in $\mathrm{NH}_{3}$ gas at $900^{\circ} \mathrm{C}$ for 15 min and then transferred to an $\mathrm{Ar}$ atmosphere at $1000^{\circ} \mathrm{C}$ for $1 \mathrm{~h}$ to remove $\mathrm{Zn}$ in the precursor and stabilize the whole carbon framework. The final catalyst was denoted as Pt-Fe-N-C. The Pt and Fe loadings were around 1.7 wt $\%$ and $2.0 \mathrm{wt} \%$, respectively.

Pt-N-C electrocatalyst. As a reference electrocatalyst, Pt-N-C was prepared from a ZIF-8 support, which was formed by mixing $1 \mathrm{mM} \mathrm{Zn}\left(\mathrm{NO}_{3}\right)_{2} \cdot 6 \mathrm{H}_{2} \mathrm{O}$ and $8.21 \mathrm{~g}$ 2-methylimidazole in a methanol solvent and following the same collecting and drying protocols as for Fe-doped ZIF-8. Similarly, $10 \mathrm{mg}$ platinum (II) acetylacetonate was homogeneously dispersed in $3 \mathrm{~mL}$ ethanol via ultrasonication until the solvent became transparent. In the meantime, $110 \mathrm{mg}$ 1,10-phenanthroline monohydrate dissolved in $10 \mathrm{~mL}$ ethanol was added to the Pt solution to provide a sufficient nitrogen source for Pt coordination. Around $400 \mathrm{mg}$ ZIF-8 was added to the above solution to form a uniform suspension. After drying at $60^{\circ} \mathrm{C}$ in a vacuum oven overnight, the solid was collected and ball milled $\left(\mathrm{ZrO}_{2}\right.$ ball, $\left.350 \mathrm{rpm}, 4 \mathrm{~h}\right)$ to uniformly 
distribute Pt and N sources on the ZIF-8 support. The mixed precursors were also initially treated in $\mathrm{NH}_{3}$ gas at $900^{\circ} \mathrm{C}$ for $15 \mathrm{~min}$ and then transferred to an Ar atmosphere at $1000^{\circ} \mathrm{C}$ for $1 \mathrm{~h}$. The final catalyst was Pt-N-C with a Pt loading of $2.3 \mathrm{wt} \%$.

\section{Physical characterization}

The TEM data were collected with a double Cs-corrected FEI Themis G2 operating at 300 kV. HAADFSTEM, EDX, and EELS were performed to obtain detailed structure and composition information on the hybrid catalyst with atomic resolution. Bulk and surface compositions were evaluated through inductively coupled plasma mass spectrometry (Varian 820) and X-ray photoelectron spectroscopy (Axis Ultra DLD), respectively. The surface area of the catalyst was measured by the Brunauer-Emmett-Teller (AUTOSORB1) method. XAS characterizations, including XANES spectroscopy and EXAFS spectroscopy, were performed at beamline 20-BM of the Advanced Photon Source at Argonne National Laboratory, using a $\mathrm{Si}(111)$ monochromator. XAS data were processed with the Athena and Artemis software package. MicroRaman (InVia (Renishaw)) was used to probe the change in the carbon support before and after durability measurement. Effluent water samples collected from the cathode gas outlet were analyzed by ion chromatography (Metrohm/881 with UV and conductivity detector) to evaluate the fluoride emissions.

\section{Electrochemical measurement}

To prepare the catalyst ink, $2.5 \mathrm{mg}$ of catalyst was uniformly dispersed in $500 \mu \mathrm{L}$ of mixed solvent (water and isopropanol at a $4: 1$ volume ratio) and $10 \mu \mathrm{L}$ of a $5 \mathrm{wt} \% \mathrm{Nafion}^{\mathrm{TM}} 117$ solution. The rotating-ring disk electrode (RRDE, $5.5 \mathrm{~mm}$ in diameter) was polished with $\mathrm{Al}_{2} \mathrm{O}_{3}$ powder $(50 \mathrm{~nm}) .10 \mu \mathrm{L}$ of catalyst ink was dropped onto the electrode. After drying in air, the thin-film electrode was evaluated by an electrochemical workstation ( $\mathrm{CHI} 760 \mathrm{E})$. A carbon rod and $\mathrm{Ag} / \mathrm{AgCl}$ were used as counter electrode and reference electrode, respectively. All potentials are referred to the reversible hydrogen electrode (RHE). 20 cycles of $\mathrm{CVs}$ in the potential range of 0 to $1.2 \mathrm{~V}$ at $100 \mathrm{mV} \mathrm{s}^{-1}$ were applied to clean the thin film in an Ar-saturated $0.1 \mathrm{M} \mathrm{HClO}_{4}$ solution, followed by taking a stable CV curve in the same potential range at $50 \mathrm{mV} \mathrm{s}^{-1}$. The ORR performance was measured in an $\mathrm{O}_{2}$-saturated $0.1 \mathrm{M} \mathrm{HClO}_{4}$ solution with a 1600 -rpm rotation rate. Linear sweep voltammetry was performed on Pt-Fe-N-C and Pt/C by positively scanning the electrode in the potential range of 0.125 to $1.0 \mathrm{~V}$ at 1 and $5 \mathrm{mV} \mathrm{s}^{-1}$, respectively. For the durability comparison, the steady-state currents of Pt-Fe-N-C and Fe-N-C were recorded from 1.0 to $0.125 \mathrm{~V}$ with a $25-\mathrm{mV}$ interval and $30 \mathrm{~s}$ dwell time for each potential.

The collection efficiency of the RRDE was first determined in an Ar-saturated $10 \mathrm{mM} \mathrm{K}{ }_{3} \mathrm{Fe}(\mathrm{CN})_{6}+1 \mathrm{M} \mathrm{KOH}$ solution. The electrode was rotated at $1600 \mathrm{rpm}$ (corresponding to the angular velocity applied during the measurement) and the amperometric i-t measurements were performed by setting the ring and disk voltages to $1.5 \mathrm{~V}$ and $0.1 \mathrm{~V}$, respectively. 
Disk: $\mathrm{Fe}(\mathrm{CN})_{6}{ }^{3-}+\mathrm{e}^{-} \rightarrow \mathrm{Fe}(\mathrm{CN})_{6}{ }^{4-}$

Ring: $\mathrm{Fe}(\mathrm{CN})_{6}^{4-} \rightarrow \mathrm{Fe}(\mathrm{CN})_{6}{ }^{3-}+\mathrm{e}^{-}$

The disk $\left(I_{d}\right)$ and ring $\left(I_{r}\right)$ currents were recorded. The measurement was repeated once with a disconnected disk to obtain another ring current $\left(\mathrm{I}_{\mathrm{r} 0}\right)$, which includes all currents (not from Fe $(\mathrm{CN})_{6}{ }^{4-}$ ) reduced on the disk. The collection efficiency could be calculated from:

$$
\mathrm{N}=\frac{\mathrm{I}_{\mathrm{r}}-\mathrm{I}_{\mathrm{r} 0}}{\mathrm{I}_{\mathrm{d}}}
$$

The measured collection efficiency $\left(\mathrm{N}_{\mathrm{C}}\right)$ was 0.42 at $1600 \mathrm{rpm}$. The $\mathrm{H}_{2} \mathrm{O}_{2} \%$ yield and electron transfer number $(n)$ of electrocatalysts were further determined in an $\mathrm{O}_{2}$-saturated $0.1 \mathrm{M} \mathrm{HClO}_{4}$ solution. The disk current $\left(i_{d}\right)$ and the ring current $\left(i_{r}\right)$ were gained by scanning the disk from 1.0 to $0.125 \mathrm{~V}$ at $1 \mathrm{mV} \mathrm{s}^{-1}$ and keeping the voltage of the ring at $1.2 \mathrm{~V}$. Four-electron and two-electron ORRs may both occur on the disk to produce $\mathrm{i}_{1}$ and $\mathrm{i}_{2}$ current, respectively. $\mathrm{H}_{2} \mathrm{O}_{2}$ produced on the disk would diffuse to the ring area and be captured and reduced to $\mathrm{H}_{2} \mathrm{O}\left(\mathrm{i}_{2 \mathrm{r}}\right)$. The $\mathrm{H}_{2} \mathrm{O}_{2} \%$ and $\mathrm{n}$ calculation equations were derived from the following steps:

$$
\begin{gathered}
\text { Faraday's Law: } \mathrm{Q}=\mathrm{nFN} \\
\text { Reaction current: } \mathrm{i}=\frac{\sigma \mathrm{Q}}{\mathrm{\sigma t}} \\
\text { Moles of product: } \mathrm{N}=\frac{\mathrm{i}^{*} \Delta \mathrm{t}}{\mathrm{nF}} \\
\text { Moles of oxygen reduced: } \mathrm{N}_{\mathrm{O}_{2}}=\frac{\Delta \mathrm{t}}{\mathrm{F}} *\left(\frac{\mathrm{i}_{1}}{4}+\frac{\mathrm{i}_{2}}{2}\right)
\end{gathered}
$$

The total number of electrons transferred: $\mathrm{n}=\frac{\mathrm{i}^{*} \Delta \mathrm{t}}{\mathrm{N}_{\mathrm{O}_{2}}{ }^{*} \mathrm{~F}}$

$$
\begin{gathered}
\mathrm{i}=\mathrm{i}_{\mathrm{d}}=\mathrm{i}_{1}+\mathrm{i}_{2}+\mathrm{i}_{2 \mathrm{r}} \\
\mathrm{n}=4 * \frac{\mathrm{i}_{1}+\mathrm{i}_{2}+\mathrm{i}_{2 \mathrm{r}}}{\mathrm{i}_{1}+\mathrm{i}_{2}} \\
\frac{\mathrm{i}_{\mathrm{r}}}{\mathrm{N}_{\mathrm{C}}}=\mathrm{i}_{2}-\mathrm{i}_{2 \mathrm{r}} \\
\mathrm{n}=4 * \frac{\mathrm{i}_{\mathrm{d}}}{\mathrm{i}_{\mathrm{d}}+\frac{\mathrm{i}_{\mathrm{r}}}{\mathrm{N}_{\mathrm{C}}}} \\
\mathrm{N}_{\mathrm{H}_{2} \mathrm{O}_{2}}=\frac{\Delta \mathrm{t}}{\mathrm{F}} *\left(\frac{\mathrm{i}_{2}}{2}-\frac{\mathrm{i}_{2 \mathrm{r}}}{2}\right) \\
\mathrm{H}_{2} \mathrm{O}_{2}=\frac{\mathrm{N}_{\mathrm{H}_{2} \mathrm{O}_{2}}}{\mathrm{~N}_{\mathrm{O}_{2}}}=2 * \frac{\mathrm{i}_{2}-\mathrm{i}_{2,}}{\mathrm{i}_{1}+2 \mathrm{i}_{2}}=2 * \frac{\frac{\mathrm{i}_{\mathrm{r}}}{\mathrm{N}_{\mathrm{C}}}}{\mathrm{i}_{\mathrm{d}}+\frac{\mathrm{i}_{\mathrm{r}}}{\mathrm{N}_{\mathrm{C}}}}
\end{gathered}
$$




\section{Fuel cell testing}

Pt-Fe-N-C catalyst was dispersed in a mixture of isopropanol, water and $5 \mathrm{wt} \%$ D $521 \mathrm{Nafion}^{\mathrm{TM}}$ dispersion at the weight ratio of 1:130:30:17. The ink was stirred for 2 days and sprayed on the GDL until the catalyst loading and corresponding Pt loading reached $0.88 \mathrm{mg} \mathrm{cm}^{-2}$ and $0.015 \mathrm{mg} \mathrm{cm}^{-2}$, respectively. A Fe-N-C cathode with $3.5 \mathrm{mg} \mathrm{cm}^{-2}$ of catalyst loading and a Pt-N-C cathode with $0.1 \mathrm{mg} \mathrm{cm}^{-2}$ of Pt loading were prepared using the same protocol. Commercial Pt/C-coated GDL with $0.1 \mathrm{mg} \mathrm{cm}^{-2} \mathrm{Pt}$ loading was used as the anode. Two GDLs were pressed on the two sides of a Nafion HP membrane at $140^{\circ} \mathrm{C}$ under 7 bar pressure for $5 \mathrm{~min}$ to make the membrane electrode assembly (MEA). Commercial Pt/C catalystcoated membranes with $0.1 \mathrm{mg} \mathrm{cm}^{-2} \mathrm{Pt}$ loading on both cathode and anode were also prepared for comparison. The performance of the MEA with a $5-\mathrm{cm}^{2}$ active area was measured using a fuel cell station (Fuel Cell Technologies). The temperature and relative humidity $(\mathrm{RH})$ were kept at $80^{\circ} \mathrm{C}$ and $100 \%$ during testing. Prior to performance measurement, an "activation" step was applied by holding the fuel cell voltage at $0.5 \mathrm{~V}$ in a $\mathrm{H}_{2}$ /air environment for 20 hours for Pt-Fe-N-C, Pt-N-C and Pt/C cathodes, as the current density gradually increased and reached a stable maximum value. In the case of the Fe-N-C cathode, keeping the voltage at $0.3 \mathrm{~V}$ in $\mathrm{H}_{2}$ /air for 3 hours is enough to active the catalyst layer. The polarization curves were recorded at the $\mathrm{H}_{2}$ and $\mathrm{O}_{2}$ flow rates of $300 \mathrm{~mL} \mathrm{~min}^{-1}$ and back pressure of 1 $\mathrm{bar}_{\text {anode }}$ and $2 \mathrm{bar}_{\text {cathode }}\left(\mathrm{bbar}_{\text {cathode }}\right.$ for Pt/C reference). Pt-Fe-N-C, Fe-N-C and Pt/C cathodes were subjected to two durability testing protocols. One consists of square-wave potential cycling at 0.6 and $0.95 \mathrm{~V}$ with each potential applied for $3 \mathrm{~s}$, following the DOE protocol for evaluating the durability of catalysts. The other is a chronoamperometric measurement at a discharge voltage of $0.6 \mathrm{~V}$ at $\mathrm{H}_{2}$ /air flow rates of $100 / 200 \mathrm{~mL} \mathrm{~min}{ }^{-1}$. The volume of effluent water produced in a certain time interval was recorded to measure the amount of fluoride emissions.

For comparison with the DOE performance target, the volume activity of the Pt-Fe-N-C in this work is also reported in $\mathrm{A} \cdot \mathrm{cm}^{-3}$ and under DOE reference conditions of 1 bar absolute pressure for both $\mathrm{H}_{2}$ and $\mathrm{O}_{2}$, $100 \% \mathrm{RH}$ and $80^{\circ} \mathrm{C}$. The testing conditions are the same as the reference conditions, except for the $\mathrm{H}_{2}$ (1.5 bar) and $\mathrm{O}_{2}(2.5 \mathrm{bar})$ absolute pressures. To convert the mass activity (MA) measured under $\mathrm{O}_{2} / \mathrm{H}_{2}$ $=2.5 / 1.5$ bar absolute pressures to volumetric activity $\left(\mathrm{V}_{\mathrm{a}}{ }^{*}\right)$ under the reference conditions of 1 bar $\mathrm{O}_{2}$ absolute pressure, the following equation has been applied ${ }^{16,25}$.

$$
V_{a}^{*}=M A \times \rho_{e f f} \times\left(\frac{P_{O_{2}}{ }^{*}}{P_{O_{2}}}\right)^{0.79} \times\left(\frac{P_{H_{2}}{ }^{*}}{P_{H_{2}}}\right)^{\frac{\alpha_{c}}{2}}
$$

where and are the reference pressure of 1 bar. While and during the measurement are 2.5 bar and 1.5 bar, respectively. is the effective density and is assumed to be $0.4 \mathrm{~g} \cdot \mathrm{cm}^{-3}$ for a non-precious-metal catalyst in a porous cathode ${ }^{26}$. is the transfer coefficient and theoretically $\leq 1$, and is generally assumed to be 1 in the calculation ${ }^{16,27}$. 


\section{Theoretical calculations}

DFT calculations were performed to explore the ORR mechanisms of Pt-Fe-N-C hybrid electrocatalysts by using the Vienna Ab-Initio Simulation Package (VASP) code. ${ }^{28,29}$ The projector augmented wave method ${ }^{30,31}$ pseudopotentials with the revised Perdew-Burke-Ernzerhof generalized gradient approximation (GGA-RPBE) ${ }^{32}$ functional, which were provided in the VASP database, were used to describe the electron-ion interactions. The plane-wave cutoff energy was set to be $400 \mathrm{eV}$. The Gaussian smearing scheme was used with a width of $0.1 \mathrm{eV}$. For structure optimizations, the total energy convergence was set to be smaller than $1 \times 10^{-5} \mathrm{eV}$, and the force convergence was set to be lower than $0.01 \mathrm{eV} / \AA ̊$ on atoms. Dipole corrections were applied in all the slab simulations. Spin polarization was considered in our calculations. The DFT-D3 method of Grimme with zero damping ${ }^{33}$ was used to include the van der Waals corrections. A vacuum slab of $16 \AA$ was added in the $z$ direction to avoid spurious periodic interactions. For carbon-based models, the lattice parameters were $14.79 \times 14.79 \times 20 \AA^{3}$ with the $(6 \times 6)$ supercell. For core-shell nanoparticles, a four-atomic-layer $(2 \times 2)$ surface unit cell was built with a Pt skin on top of PtFe(111) at the substrate's lattice constants $\left(5.39 \times 5.39 \times 22.63 \AA^{3}\right)$. During geometry optimizations, the carbon-based models were fully relaxed, and the top two layers with adsorbates on metal slabs were optimized. For the Brillouin zone integrations, the Monkhorst-Pack ${ }^{34}$ grids of $3 \times 3 \times 1$ and $5 \times 5 \times 1$ were sampled for carbon-based models and core-shell slab models, respectively. The $\mathrm{GGA}+\mathrm{U}(\mathrm{U}=3.29 \mathrm{eV})$ was used to describe the localized $3 d$ orbital electrons for Fe atoms, considering the magnetic moment of Fe correctly ${ }^{35-37}$.

The calculation of Gibbs free energy for each elementary step is based on the computational hydrogen electrode scheme proposed by Norskov and co-workers ${ }^{38}$, which is calculated at $298 \mathrm{~K}$ and 1 atmosphere according to the equation $\mathrm{G}=\mathrm{E}_{\text {total }}+\mathrm{ZPE}-\mathrm{TS}$, where $\mathrm{E}_{\text {total }}$ can be directly obtained from DFT calculations, and ZPE and TS are the zero-point vibrational energy correction and entropy correction, respectively. The ORR reaction pathway on various active sites was considered as follows:

$$
\begin{gathered}
\mathrm{O}_{2}+\left(\mathrm{H}^{+}+\mathrm{e}^{-}\right)+* *{ }^{*} \mathrm{OOH} \\
* \mathrm{OOH}+\left(\mathrm{H}^{+}+\mathrm{e}^{-}\right)={ }^{*} \mathrm{O}+\mathrm{H}_{2} \mathrm{O} \\
{ }^{*} \mathrm{O}+\left(\mathrm{H}^{+}+\mathrm{e}^{-}\right)={ }^{*} \mathrm{OH} \\
{ }^{*} \mathrm{OH}+\left(\mathrm{H}^{+}+\mathrm{e}^{-}\right)=*+\mathrm{H}_{2} \mathrm{O}
\end{gathered}
$$

Therefore, at $\mathrm{U}=0$ (vs RHE) and standard condition, the free energy for elementary steps can be calculated as follows: 


$$
\begin{gathered}
\Delta \mathrm{G} 1=\mathrm{G}\left({ }^{*} \mathrm{OOH}\right)-\mathrm{G}\left({ }^{*}\right)-\mathrm{G}\left(\mathrm{O}_{2}\right)-1 / 2 \mathrm{G}\left(\mathrm{H}_{2}\right) \\
\Delta \mathrm{G} 2=\mathrm{G}\left({ }^{*} \mathrm{O}\right)+\mathrm{G}\left(\mathrm{H}_{2} \mathrm{O}\right)-\mathrm{G}\left({ }^{*} \mathrm{OOH}\right)-1 / 2 \mathrm{G}\left(\mathrm{H}_{2}\right) \\
\Delta \mathrm{G} 3=\mathrm{G}\left({ }^{*} \mathrm{OH}\right)-\mathrm{G}\left({ }^{*} \mathrm{O}\right)-1 / 2 \mathrm{G}\left(\mathrm{H}_{2}\right) \\
\Delta \mathrm{G} 4=\mathrm{G}\left({ }^{*}\right)+\mathrm{G}\left(\mathrm{H}_{2} \mathrm{O}\right)-\mathrm{G}\left({ }^{*} \mathrm{OH}\right)-1 / 2 \mathrm{G}\left(\mathrm{H}_{2}\right)
\end{gathered}
$$

The bias effect is considered by shifting the energy state by $\Delta G_{U}=-n e U$, where $U$ is the electrode applied potential relative to the RHE, $e$ is the transferred charge, and $n$ is the number of the transferred protonelectron pairs. The detailed results are summarized in Supplementary Table 4.

\section{Declarations}

Data availability. The data that support the findings of this study are available from the corresponding authors upon reasonable request.

\section{Acknowledgments}

This work was support by Shenzhen Science and Technology Innovation Committee (SGDX2019081623340748), The Research Grant Council of the Hong Kong Special Administrative Region (N_HKUST610/17), The National Key R\&D Program of China (No. 2017YFB0102900) and National Natural Science Foundation of China (No. 21802065). This research used resources of the Advanced Photon Source, an Office of Science User Facility operated for the U.S. Department of Energy (DOE) Office of Science by Argonne National Laboratory and was supported by the U.S. DOE under Contract No. DE-AC02-06CH11357, No. DE-AC02-06CH11357, and the Canadian Light Source and its funding partners. The authors thank the Tianhe-2 National Supercomputer Center in Guangzhou and the high-performance computing service in HKUST and the TEM work performed at the Pico-center in the SUSTech core research facility.

\section{Author contributions}

M.S. K. A and M.G supervised the whole project. F.X. and M.S. conceived the idea and designed the experiments. F.X. performed catalysts development and performance evaluation. M.G. Q.W., Y.Z. and D.W. carried out electron microscopy characterization. K.A., G.X., I.H and C.S performed synchrotron characterization and relative data analysis. X.Q. carried out simulation parts. F.X., H.W., S.Z., J.L., W.H., J.W and Z.W perform material preparation and general characterizations. F.X., Q.W., G.X, X.Q., M.S, K.A. and $M, G$ analyzed the data and wrote the manuscript. All authors discussed the results and commented on the manuscript. F, X. Q.W., X.G and X.Q. contributed equally.

\section{Competing interests}

The authors declare no competing financial interests. 
Additional Information

Supplementary information is available for this paper.

\section{Corresponding Author}

gum@sustech.edu.cn, amine@anl.gov, kemshao@ust.hk

\section{References}

1 Shao, M., Chang, Q., Dodelet, J.-P. \& Chenitz, R. Recent advances in electrocatalysts for oxygen reduction reaction. Chem. Rev. 116, 3594-3657 (2016).

2 Kodama, K., Nagai, T., Kuwaki, A., Jinnouchi, R. \& Morimoto, Y. Challenges in applying highly active Pt-based nanostructured catalysts for oxygen reduction reactions to fuel cell vehicles. Nat. Nanotechnol. $16,140-147$ (2021).

3 Ott, S. et al. Ionomer distribution control in porous carbon-supported catalyst layers for high-power and low Pt-loaded proton exchange membrane fuel cells. Nat. Mater. 19, 77-85 (2020).

4 Xie, X. et al. Performance enhancement and degradation mechanism identification of a singleatom Co-N-C catalyst for proton exchange membrane fuel cells. Nat. Catal. 3, 1-11 (2020).

5 Wang, Y. et al. Advanced Electrocatalysts with Single-Metal-Atom Active Sites. Chem. Rev. 120, 12217-12314 (2020).

6 Banham, D. \& Ye, S. Current status and future development of catalyst materials and catalyst layers for proton exchange membrane fuel cells: An industrial perspective. ACS Energy Lett. 2, 629-638 (2017).

7 Kongkanand, A. \& Mathias, M. F. The priority and challenge of high-power performance of lowplatinum proton-exchange membrane fuel cells. J. Phys. Chem. Lett. 7, 1127-1137 (2016).

8 Chen, C. et al. Highly crystalline multimetallic nanoframes with three-dimensional electrocatalytic surfaces. Science 343, 1339-1343 (2014).

9 Xiao, F. et al. Recent Advances in Electrocatalysts for Proton Exchange Membrane Fuel Cells and Alkaline Membrane Fuel Cells. Adv. Mater. n/a, 2006292 (2021).

10 Chong, L. et al. Ultralow-loading platinum-cobalt fuel cell catalysts derived from imidazolate frameworks. Science 362, 1276-1281 (2018).

11 Jones, G. A. \& Keigwin, L. D. Evidence from Fram Strait (78 N) for early deglaciation. Nature 336, 56-59 (1988). 
12 Harvey, A. S. Synthesis and atomic-level characterization of rare earth oxide nanoparticles with EELS and XAS. (Ph.D. Thesis, University of California, Davis, 2005).

13 Jung, N. et al. Organic-inorganic hybrid PtCo nanoparticle with high electrocatalytic activity and durability for oxygen reduction. NPG Asia Mater. 8, e237 (2016).

14 Zhang, N. et al. High-purity pyrrole-type $\mathrm{FeN}_{4}$ sites as a superior oxygen reduction electrocatalyst. Energy Environ. Sci. 13, 111-118 (2020).

15 Liu, Q. et al. Sequential Synthesis and Active-Site Coordination Principle of Precious Metal SingleAtom Catalysts for Oxygen Reduction Reaction and PEM Fuel Cells. Adv. Energy Mater. 10, 2000689 (2020).

16 Lefèvre, M., Proietti, E., Jaouen, F. \& Dodelet, J.-P. Iron-based catalysts with improved oxygen reduction activity in polymer electrolyte fuel cells. Science 324, 71-74 (2009).

17 Gan, L., Heggen, M., O’Malley, R., Theobald, B. \& Strasser, P. Understanding and Controlling Nanoporosity Formation for Improving the Stability of Bimetallic Fuel Cell Catalysts. Nano Lett. 13, 1131-1138 (2013).

18 Wang, D. et al. Structurally ordered intermetallic platinum-cobalt core-shell nanoparticles with enhanced activity and stability as oxygen reduction electrocatalysts. Nat. Mater. 12, 81-87 (2013).

19 Qiao, M. et al. Hierarchically Ordered Porous Carbon with Atomically Dispersed $\mathrm{FeN}_{4}$ for Ultraefficient Oxygen Reduction Reaction in Proton-Exchange Membrane Fuel Cells. Angew. Chem. Int. Ed. 59, 2688-2694 (2020).

20 Zhang, G., Chenitz, R., Lefèvre, M., Sun, S. \& Dodelet, J.-P. Is iron involved in the lack of stability of $\mathrm{Fe} / \mathrm{N} / \mathrm{C}$ electrocatalysts used to reduce oxygen at the cathode of PEM fuel cells? Nano Energy 29, 111125 (2016).

21 Tsuneda, T. Fenton reaction mechanism generating no $\mathrm{OH}$ radicals in Nafion membrane decomposition. Sci. Rep. 10, 18144 (2020).

22 Choi, C. H. et al. Stability of Fe-N-C catalysts in acidic medium studied by operando spectroscopy. Angew. Chem. Int. Ed. 54, 12753 (2015).

23 Xiao, F. et al. Nitrogen-coordinated single iron atom catalysts derived from metal organic frameworks for oxygen reduction reaction. Nano Energy 61, 60-68 (2019).

24 Xiao, F. et al. Durable hybrid electrocatalysts for proton exchange membrane fuel cells. Nano Energy 77, 105192 (2020). 
25 Neyerlin, K., Gu, W., Jorne, J. \& Gasteiger, H. A. Determination of catalyst unique parameters for the oxygen reduction reaction in a PEMFC. J. Electrochem. Soc. 153, 1955-1963 (2006).

26 Gasteiger, H. A., Kocha, S. S., Sompalli, B. \& Wagner, F. T. Activity benchmarks and requirements for Pt, Pt-alloy, and non-Pt oxygen reduction catalysts for PEMFCs. Appl. Catal. B 56, 9-35 (2005).

27 Chung, H. T. et al. Direct atomic-level insight into the active sites of a high-performance PGM-free ORR catalyst. Science 357, 479-484 (2017).

28 Kresse, G. \& Hafner, J. Ab initio molecular dynamics for liquid metals. Phys. Rev. B 47, 558-561 (1993).

29 Kresse, G. \& Furthmüller, J. Efficiency of ab-initio total energy calculations for metals and semiconductors using a plane-wave basis set. Comput. Mater. Sci. 6, 15-50 (1996).

30 Kresse, G. \& Joubert, D. From ultrasoft pseudopotentials to the projector augmented-wave method. Phys. Rev. B 59, 1758-1775 (1999).

31 Blöchl, P. E. Projector augmented-wave method. Phys. Rev. B 50, 17953-17979 (1994).

32 Hammer, B., Hansen, L. B. \& Nørskov, J. K. Improved adsorption energetics within densityfunctional theory using revised Perdew-Burke-Ernzerhof functionals. Phys. Rev. B 59, 7413-7421 (1999).

33 Grimme, S., Antony, J., Ehrlich, S. \& Krieg, H. A consistent and accurate ab initio parametrization of density functional dispersion correction (DFT-D) for the 94 elements H-Pu. J. Chem. Phys. 132, 154104 (2010).

34 Monkhorst, H. J. \& Pack, J. D. Special points for Brillouin-zone integrations. Phys. Rev. B 13, 51885192 (1976).

35 Dudarev, S., Botton, G., Savrasov, S., Humphreys, C. \& Sutton, A. Electron-energy-loss spectra and the structural stability of nickel oxide: An LSDA+ U study. Phys. Rev. B 57, 1505-1509 (1998).

36 Jiang, J. et al. Atomic-level insight into super-efficient electrocatalytic oxygen evolution on iron and vanadium co-doped nickel (oxy) hydroxide. Nat. Commun. 9, 1-12 (2018).

$37 \mathrm{Xu}, \mathrm{H}$., Cheng, D., Cao, D. \& Zeng, X. C. A universal principle for a rational design of single-atom electrocatalysts. Nat. Catal. 1, 339-348 (2018).

38 Nørskov, J. K. et al. Origin of the Overpotential for Oxygen Reduction at a Fuel-Cell Cathode. J. Phys. Chem. B 108, 17886-17892 (2004).

\section{Figures}



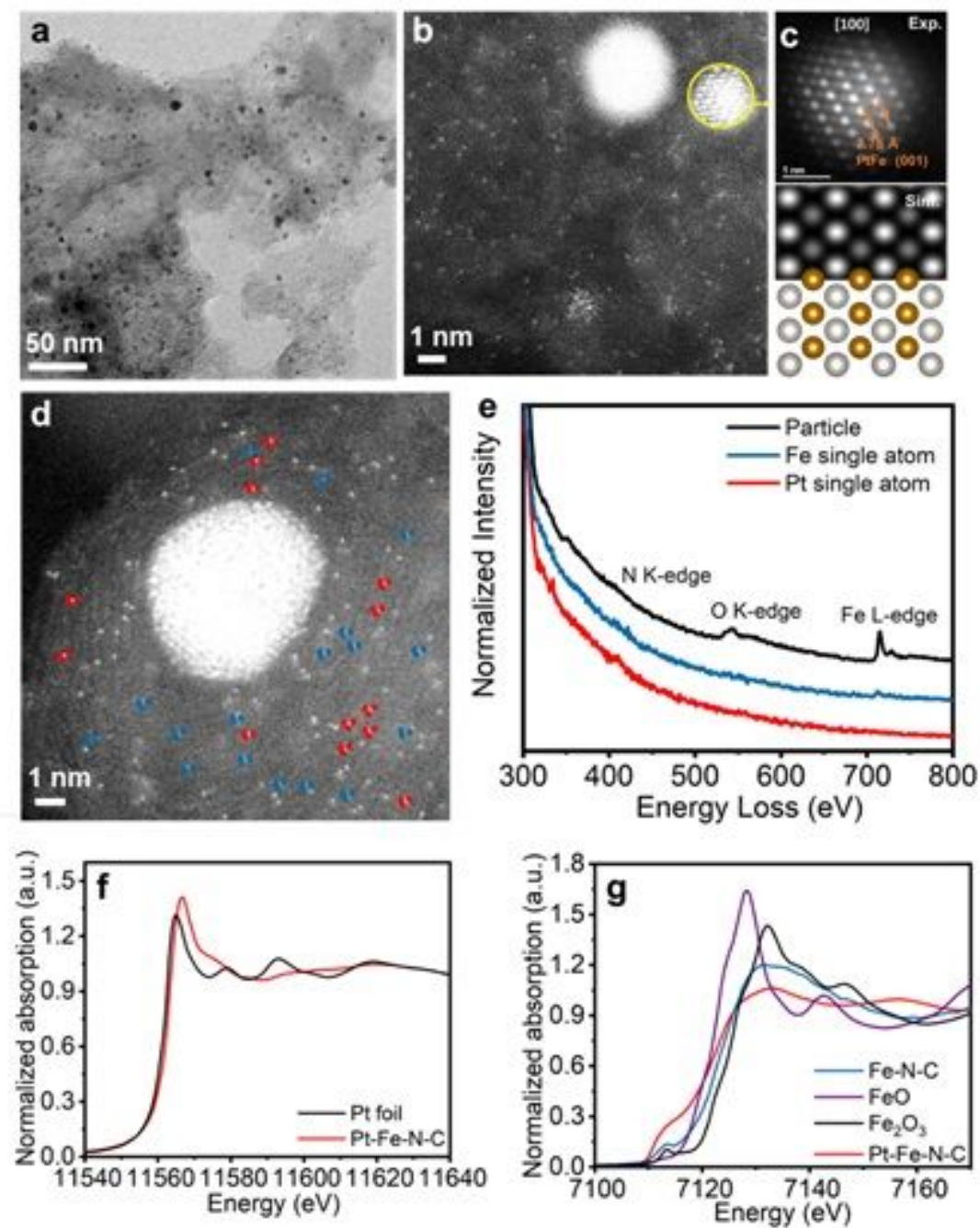

\section{Figure 1}

Electron microscopy and synchrotron characterizations of multiple active sites in Pt-Fe-N-C electrocatalyst. a, b, TEM image (a) and HAADF-STEM image (b) of the hybrid Pt-Fe-N-C catalyst. c, HAADF-STEM image of an individual particle with simulated STEM image and atomic models along [100] zone axis (white and yellow spheres represent $\mathrm{Pt}$ and Fe, respectively). d, e, HAADF-STEM image (d) and corresponding EELS analysis (e) to verify the Pt and Fe coexistence at the atomic level in Pt-Fe-N-C electrocatalyst (the spots in blue and red dashed circles are ascribed to Fe and Pt single atoms, respectively). f, g, Comparisons of XANES spectra among Pt-Fe-N-C, Fe-N-C, Fe foil, FeO, Fe2O3, and Pt foil: Pt L3-edge (f) and Fe K-edge (g). 

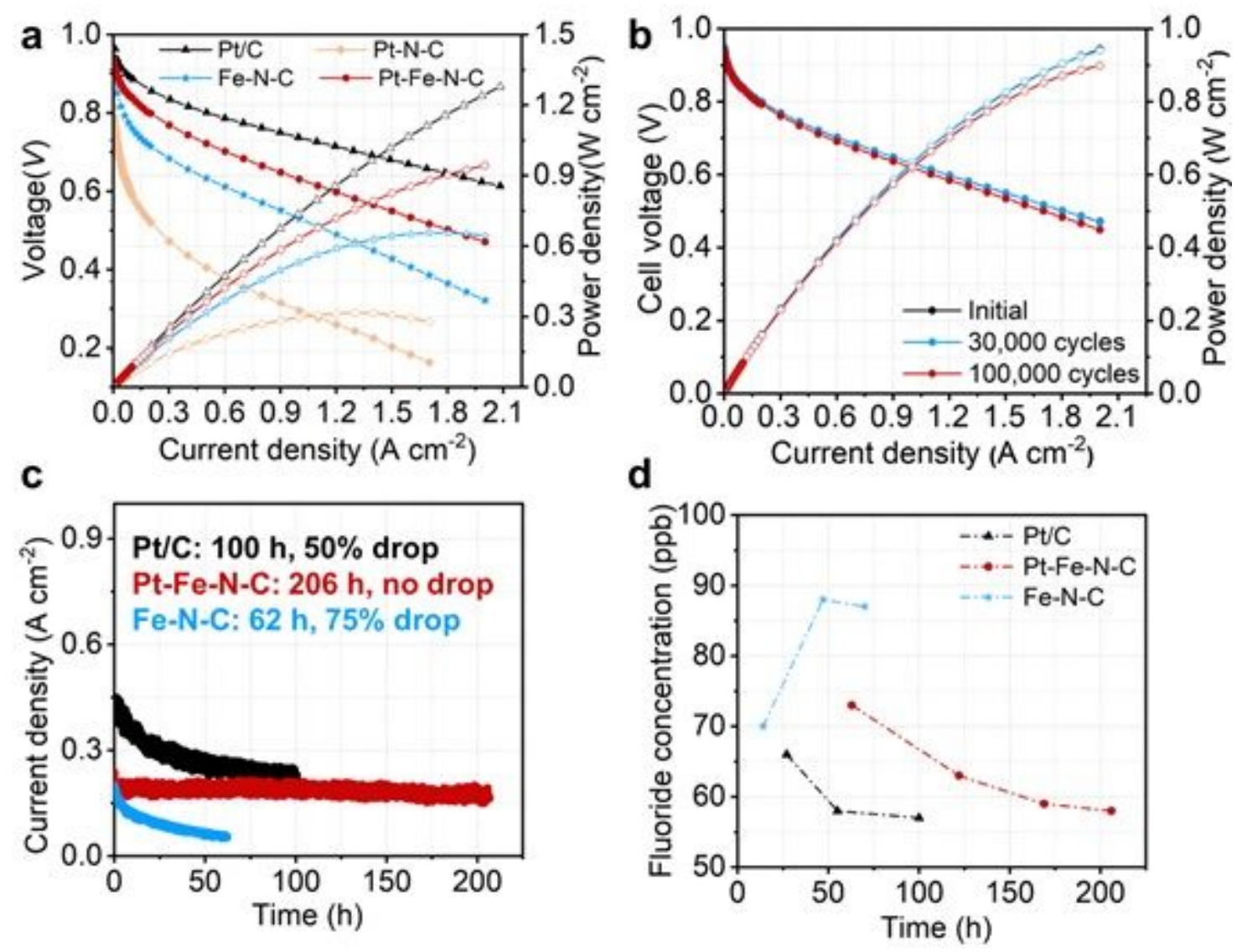

Figure 2

Activity and durability evaluation of Pt-Fe-N-C cathode in the fuel cell device. $\mathrm{H} 2 / \mathrm{O} 2$ fuel cell polarization (solid symbols and left y-axis) and power density (hollow symbols and right y-axis) plots with a $\mathrm{Pt}$ loading of $0.1 \mathrm{mgPt} \mathrm{cm}-2$ for Pt/C (black triangles) and Pt-N-C (yellow diamonds), $0.015 \mathrm{mgPt} \mathrm{cm}-2$ for Pt-Fe-N-C (red circles), and $3.5 \mathrm{mg} \mathrm{cm}-2$ catalyst loading for Fe-N-C (blue stars) in the cathode. b, H2/O2 fuel cell polarization (solid symbols and left y-axis) and power density (hollow symbols and right $y$-axis) plots of Pt-Fe-N-C cathode before cycling (black) and after 30,000 (blue) and 100,000 (red) potential cycles between 0.6 and $0.95 \mathrm{~V}$. The black and blue curves are overlapping because of negligible decay after 30,000 cycles. c, d, Current density as a function of time at $0.6 \mathrm{~V}$ in H2/air environment (c) and fluoride concentration in water collected in fuel cells using Pt/C, Fe-N-C and Pt-Fe-N-C catalysts in cathode during potential hold at $0.6 \mathrm{~V}$ (d). 

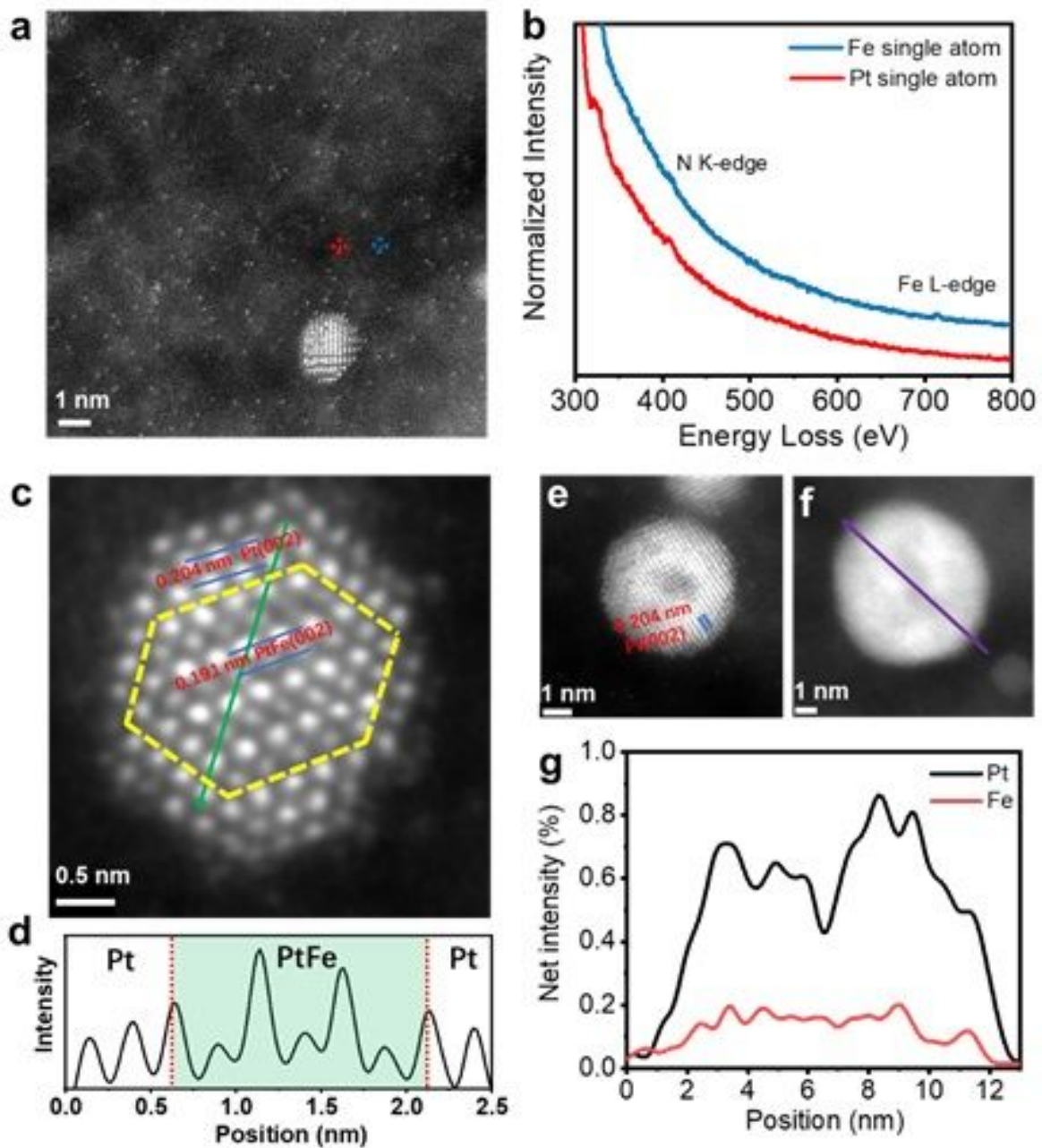

Figure 3

Electron microscopy characterization of Pt-Fe-N-C electrocatalysts after durability measurement. a, HAADF-STEM image of Pt-Fe-N-C catalyst after 100,000 cycles, in which the blue and red dashed circles denote Fe and Pt single atoms, respectively. b, EELS analysis to probe the well-preserved Pt-N and Fe-N configurations. c, d, HAADF-STEM image (c) and corresponding line profiles (d) for HAADF intensity analysis labeled in (c) to illustrate the PtFe@Pt core-shell structure. e, f, g, HAADF-STEM images of larger Pt-Fe-N-C catalyst particles after 100,000 cycles (e, f) and EDX line profile (g) along the purple arrow in (f), showing the mass content differential between Fe and Pt and further revealing the formation of a pit in the center. 

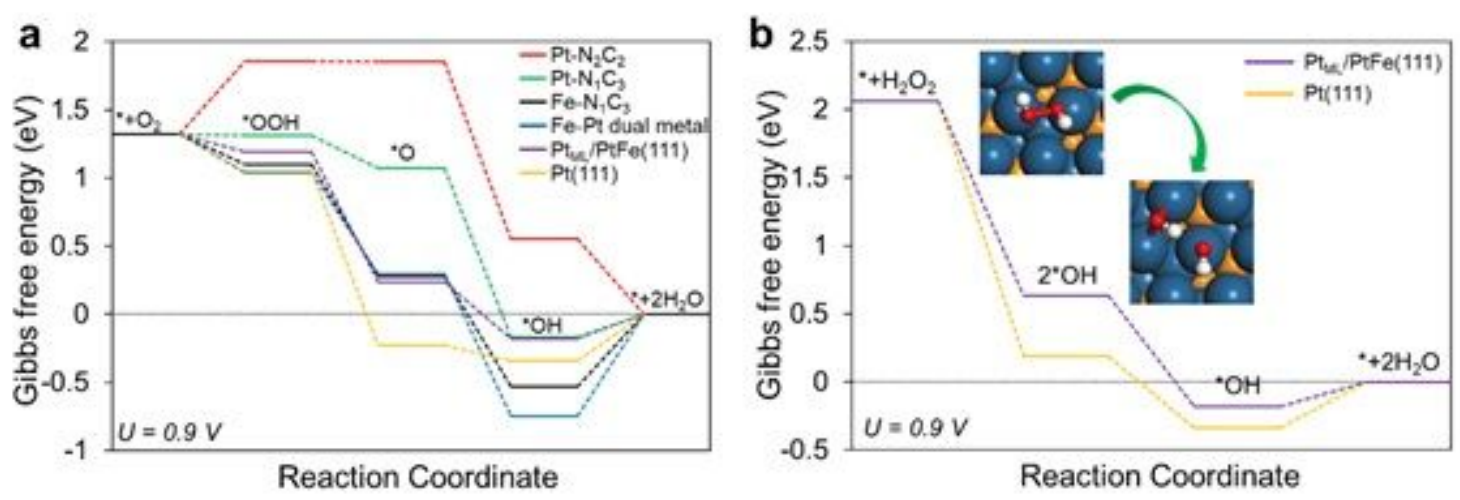

\section{Figure 4}

Theoretical study to illustrate the origins of the high activity and durability of Pt-Fe-N-C. a, Gibbs free energy diagram of ORR on various possible active sites at $U=0.9 \mathrm{~V}$. b, Gibbs free energy diagram of $\mathrm{H} 2 \mathrm{O} 2$ reduction reaction on $\mathrm{PtML} / \mathrm{PtFe}(111)$ and $\mathrm{Pt}(111)$. The inserted atomic figures show the $\mathrm{H} 2 \mathrm{O} 2$-to$2{ }^{*} \mathrm{OH}$ conversion on PtML/PtFe(111). Color code: Pt: dark blue; Fe: orange; O: red; $\mathrm{H}$ : white.

\section{Supplementary Files}

This is a list of supplementary files associated with this preprint. Click to download.

- Supportinginformation.pdf 